\title{
Hydrological differentiation and spatial distribution of high altitude wetlands in a semi-arid Andean region derived from satellite data
}

\author{
M. Otto ${ }^{1}$, D. Scherer ${ }^{1}$, and J. Richters ${ }^{2}$ \\ ${ }^{1}$ Technische Universität Berlin, Department of Ecology, Chair of Climatology, Rothenburgstraße 12, 12165 Berlin, Germany \\ ${ }^{2}$ Lohmeyer Consulting Engineers GmbH \& Co. KG, Karlsruhe, Germany
}

Received: 4 November 2010 - Published in Hydrol. Earth Syst. Sci. Discuss.: 28 January 2011

Revised: 21 April 2011 - Accepted: 3 May 2011 - Published: 31 May 2011

\begin{abstract}
High Altitude Wetlands of the Andes (HAWA) belong to a unique type of wetland within the semi-arid high Andean region. Knowledge about HAWA has been derived mainly from studies at single sites within different parts of the Andes at only small time scales. On the one hand, HAWA depend on water provided by glacier streams, snow melt or precipitation. On the other hand, they are suspected to influence hydrology through water retention and vegetation growth altering stream flow velocity. We derived HAWA land cover from satellite data at regional scale and analysed changes in connection with precipitation over the last decade. Perennial and temporal HAWA subtypes can be distinguished by seasonal changes of photosynthetically active vegetation (PAV) indicating the perennial or temporal availability of water during the year. HAWA have been delineated within a region of $12800 \mathrm{~km}^{2}$ situated in the Northwest of Lake Titicaca. The multi-temporal classification method used Normalized Differenced Vegetation Index (NDVI) and Normalized Differenced Infrared Index (NDII) data derived from two Landsat ETM+ scenes at the end of austral winter (September 2000) and at the end of austral summer (May 2001). The mapping result indicates an unexpected high abundance of HAWA covering about $800 \mathrm{~km}^{2}$ of the study region (6\%). Annual HAWA mapping was computed using NDVI 16-day composites of Moderate Resolution Imaging Spectroradiometer (MODIS). Analyses on the relation between HAWA and precipitation was based on monthly precipitation data of the Tropical Rain Measurement Mission (TRMM 3B43) and MODIS Eight Day Maximum Snow Extent data (MOD10A2) from 2000 to 2010. We found HAWA subtype specific dependencies on precipitation conditions. A strong relation exists between perennial HAWA and snow fall $\left(r^{2}: 0.82\right)$ in dry austral winter months (June to August) and
\end{abstract}

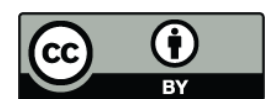

Correspondence to: M. Otto (marco.otto@klima.tu-berlin.de) between temporal HAWA and precipitation $\left(r^{2}: 0.75\right)$ during austral summer (March to May). Annual changes in spatial extend of perennial HAWA indicate alterations in annual water supply generated from snow melt.

\section{Introduction}

High Altitude Wetlands (HAWs) are situated in many mountain regions of the world (e.g., Himalaya or Alps). HAWs can be described as areas of swamp, marsh, meadow, fen or peatland whether natural or artificial, perennial or temporary, with water that is stagnant or flowing, fresh, brackish, or saline (Chatterjee et al., 2010). Although there is no scientific definition of HAWs, we would use the following general working definition: HAWs can be seen as any kind of temporarily or perennial water saturated ground above the natural forest border and below the snow line within any high mountain region on earth.

HAWs of the arid and semi-arid region of the Andes (HAWA) are situated in environments of relatively low annual precipitation and soil moisture deficits within a region also known as Puna (Wilcox et al., 1986). HAWA exist at hydrological and altitudinal limits for plant life in the cold and arid high Andean grasslands of Peru, Bolivia, Chile and Argentina. In the central parts of the Andes $\left(16^{\circ} \mathrm{S}\right)$, they occur between $4000 \mathrm{~m}$ a.s.l. and $5000 \mathrm{~m}$ a.s.1., and in the southern parts $\left(27^{\circ} \mathrm{S}\right.$ ) between $2000 \mathrm{~m}$ a.s.l. and $3000 \mathrm{~m}$ a.s.l. (Scott and Carbonell, 1986). The Convention on Wetlands of International Importance (Ramsar Convention) compiled a list of wetlands, which includes HAWA due to their importance for sustaining biodiversity including endemic flora and fauna of the Puna region. HAWA also play a critical role for local livestock grazing of the Andean camelid species like wild Vicuña (Vicugna vicugna), Guanaco (Lama guanicoe) and domesticated forms like Alpaca (Vicugna pacos) or Lama (Lama glama) (Moreau et al., 2003). Knowledge about HAWA has

Published by Copernicus Publications on behalf of the European Geosciences Union. 


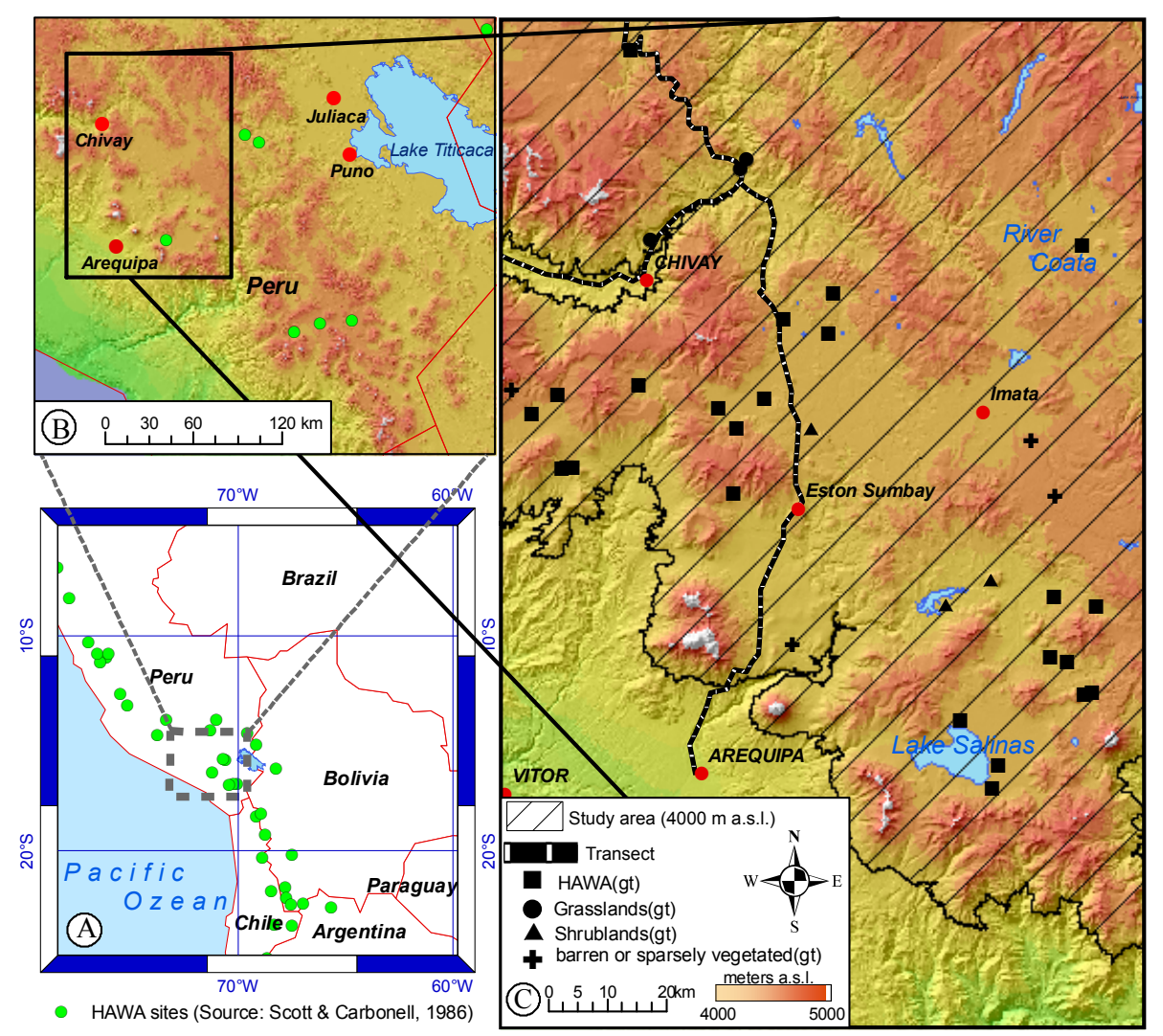

Fig. 1. Location of the study region within the known geographic range of HAWA (A, B) and ground-truth data (gt) above $4000 \mathrm{~m}$ a.s.1. (C).

been derived mainly from botanical studies within different parts of the Andes (e.g., Ruthsatz, 1993). HAWA depend on water provided by glacier streams, snow melt or precipitation. HAWA are also suspected to influence regional hydrology due to their water retention capacity and vegetation growth altering stream flow velocity (Earle et al., 2003). However, little is known about the relation between regional climate and hydrology of HAWA on the background of projected changes in temperature and precipitation within the Andes (Vuille et al., 2008).

Knowledge on spatial variability of HAWA is nonsystematic and incomplete (Naranjo, 1995). A new HAWA land cover dataset is needed for investigating relations between precipitation and vegetation changes as a proxy for hydrological differentiation of HAWA. Thus, the first objective of the study was to determine spatial extent, distribution and composition of HAWA within a subregion of their known geographic range. For this reason, we first developed a HAWA mapping design incorporating HAWA subtypes based on specific vegetation changes and changes in water availability as consequences of the main hydrological processes. The relationship between water sources and vegetation dynamics of HAWA has not yet been investigated in detail (Squeo et al., 2006). Hence, the second objective of the study was focused on analysing this relation based on annual land cover data of different HAWA subtypes and precipitation data.

Since it is difficult to obtain spatially and temporally consistent information on HAWA due to their often isolated and remote locations, a HAWA mapping procedure was designed for the utilisation of vegetation remote-sensing data. The potential for continuous monitoring of HAWA applying remotesensing data from Moderate Resolution Imaging Spectroradiometer (MODIS) was quantitatively assessed. Finally HAWA land cover change was computed for each year between 2000 and 2010. The resulting time series of annual HAWA land cover was used to analyse relations between precipitation, snow cover and spatial alterations of the HAWA subtypes.

\section{Study region}

The study region is located on the western slopes of the South Peruvian Andes between $15^{\circ} 15^{\prime}$ and $16^{\circ} 35^{\prime} \mathrm{S}$ latitude and $70^{\circ} 51^{\prime}$ and $71^{\circ} 52^{\prime} \mathrm{W}$ longitude covering a total area of approx. $12800 \mathrm{~km}^{2}$ above $4000 \mathrm{~m}$ a.s.l. within the semi-arid high Andean mountains. The study region was selected because of its central position within the known HAWA geographic range (Fig. 1a) containing different types of the Puna region characterised by the differences in annual 
precipitation and duration of humid season (wet season). Most precipitation occurs in austral summer between October and May. The north-eastern part belongs to the moist Puna belt northwest of Lake Titicaca (Fig. 1a and b) with annual precipitation of more than $500 \mathrm{~mm}$ and five to six humid months. The south-western part of the study region belongs to the dry Puna belt where mean annual precipitation is lower, varying between $300 \mathrm{~mm}$ and $500 \mathrm{~mm}$ during three to four humid months (Baied and Wheeler, 1993; Richter, 1981; Troll, 1968).

\section{Data and methods for HAWA mapping}

\subsection{Pre-processing of remote-sensing data}

Landsat ETM+ data has been widely used for the investigation on wetlands (e.g., Ozesmi and Bauer, 2002). For mapping of HAWA in dry and in wet season, we utilized two cloud-free, terrain corrected Landsat ETM+ datasets at $30 \mathrm{~m}$ spatial resolution (L1T) of 28 September 2000 and of 5 May 2001(provided by the US Geological Survey website). Atmospheric correction was not applied since the comparison of spectral index 5th percentile $\left(P_{5 \%}\right)$ and of 95 th percentile $\left(P_{95 \%}\right)$ thresholds of bare soil (B \& S) land cover ground-truth data revealed insignificant differences between Landsat ETM+ $\left(P_{5 \%}: 0.02, P_{95 \%}: 0.06\right)$ and MODIS data ( $P_{5 \%}$ : 0.03, $P_{95 \%}$ : 0.06).

The spectral response of wetlands has shown to be similar to the spectral response of irrigated crop lands, which makes it difficult to differentiate both land covers (Ozesmi and Bauer, 2002). Lower altitude limit of HAWA (4000 m a.s.1.) within the study region is equal to the maximum altitude limit for most common Andean crops (Tapia, 2000). Hence, the study region was delineated applying this altitude limit using the Digital Terrain Model (DTM) derived from data of the Shuttle Radar Topography Mission (SRTM Version 3). The DTM was also applied for generating a shadow mask based on the sun elevation and azimuth values of each Landsat ETM+ scene.

The HAWA mapping procedure, based on the developed HAWA mapping design, was analogously applied to a MODIS spectral index dataset derived from daily surface reflectance data (MOD09 and MOD02) for the same days as for Landsat ETM+. Landsat ETM+ and MODIS have different spatial resolutions as described by Chander et al. (2009) (Landsat ETM+) and Barnes et al. (1998) (MODIS). In order to quantitatively assess the HAWA mapping results, the MODIS input data was converted to spatial resolution of the Landsat ETM+ grid applying bilinear interpolation.

\section{Spectral indices}

Spectral indices were computed to differentiate HAWA subtypes and discriminate between HAWA and other land covers through thresholds based on their absolute differences and differences in seasonality. Satellite instruments measure solar radiation reflected by vegetation in certain spectral bands. Spectral reflectance data can be converted into vegetation indices. Many of these indices correlate well with e.g., vegetation amount, the fraction of absorbed photosynthetically active radiation (PAR) or unstressed vegetation conductance and photosynthetic capacity (Myneni et al., 1995). We refer to the term Photosynthetic Active Vegetation (PAV) as land cover containing unstressed vegetation of high photosynthetic capacity enabling an efficient use of PAR. Therefore, Normalized Difference Vegetation Index (NDVI) was used as a measure of PAV based on spectral change in reflectance caused by chlorophyll absorption in red wavelengths ( $\left.\rho_{\text {Red }}\right)$ and leaf additive reflectance in near-infrared wavelengths $\left(\rho_{\text {NIR }}\right)$ (Jackson and Huete, 1991). Other studies applying NDVI for biomass assessment of HAWA in Bolivia demonstrated their suitability for vegetation analysis taking into account the low atmospheric effects due to high altitude, and the low influence of soil background due to dense HAWA vegetation cover (Moreau et al., 2003). The NDVI has been known for its strong relation to precipitation. This relation could even be applied to downscale precipitation data of lower spatial resolution utilizing NDVI data of higher spatial resolution (Immerzeel et al., 2009). For this study, NDVI values were derived from near-infrared band $\left(\rho_{\mathrm{NIR}}\right)$ and red band $\left(\rho_{\text {Red }}\right)$ by:

$\mathrm{NDVI}=\frac{\rho_{\mathrm{NIR}}-\rho_{\mathrm{Red}}}{\rho_{\mathrm{NIR}}+\rho_{\mathrm{Red}}}$.

A second spectral index, i.e., the Normalized Difference Infrared Index (NDII), was applied to discriminate parts dominated by water surfaces or water oversaturation within HAWA. The NDII is more correlated with canopy moisture than the NDVI due to the spectral response of water and soil moisture in the short-wave infrared band $\left(\rho_{\mathrm{SWIR}}\right)$ (Hardisky et al., 1983). The NDII has the ability of retrieving vegetation water content at $30 \mathrm{~m}$ spatial resolution and was computed by Davidson et al. (2006):

$\mathrm{NDII}=\frac{\rho_{\mathrm{NIR}}-\rho_{\mathrm{SWIR}}}{\rho_{\mathrm{NIR}}+\rho_{\mathrm{SWIR}}}$.

\subsection{Ground-truth data acquisition}

HAWA ground-truth sites were documented during field visits obtaining GPS coordinates and photographs (as e.g., in Fig. 3) along two transects (Fig. 1c) within the study region at the end of austral winter in September 2006. Ground-truth data of four HAWA sites, three Grassland (Gra) sites, two Shrubland (Shr) sites and three sites of Barren or Sparsely vegetated ground (B \& S) were collected recording GPS waypoints within or close to homogeneous areas during the field trips. Spatial extent of each ground-truth site was digitized as regions of interest (ROI) through visual selection of homogeneous areas close to recollected GPS coordinates using a false colour image of Landsat ETM+ of September 2000. 
To minimize mapping errors during visual digitalisation of the ground-truth data, five hundred randomly sampled grid values were computed from ground-truth ROI-mask for each land cover class (HAWA(gt), Gra(gt), Shr(gt) and B \& S(gt)). The resulting new mask was used to compute spectral index thresholds for each land cover and remote-sensing dataset.

Besides the ground-truth data obtained during the field visits, we utilized additional information from different sources to generate independent HAWA test sites (Fig. 1c) as a basis for formal accuracy assessment of the HAWA mapping result. Land cover inventories like Topographic Map sheets of the Peruvian national topographic map (TMP) (IAI, 2010) and the natural resource map (INRENA, 2002) contain information on potential HAWA sites at regional scales. Scott and Carbonell (1986) incorporated information on HAWA geographic distribution for the neotropical region at continental scale (see Fig. 1a). The Ramsar list of wetlands of international importance contains information on reported HAWA locations and properties within a global wetland inventory (Wetlands International, 2010). These datasets where utilized to identify about 600 potential HAWA test sites within the study region. As a decision criterion, we only selected potential HAWA sites as test sites if they were mapped in at least two of the four above mentioned sources. As a result, 19 HAWA test sites were digitalised computing a HAWA test site ROI-mask based on the Landsat ETM+ false colour image. The final HAWA test site dataset consists of a thousand randomly stratified sampled grid values derived from the HAWA test site ROI-mask.

A HAWA mapping criterion is also based on an altitude threshold regarding altitude limits for irrigated crop lands. Therefore, way points were recorded during field visits representing ground-truth sites along two transects of altitudinal gradients from $5000 \mathrm{~m}$ a.s.l. to $1500 \mathrm{~m}$ a.s.l. (Fig. 1c). Thus, the information on altitudinal thresholds for HAWA found in literature could be validated for the study region based on ground-truth information.

\subsection{Mapping of HAWA}

\subsubsection{The concept of HAWA subtypes}

Based on a literature review, an evaluation of existing land cover inventories, field visits of ground-truth sites and following our general definition of HAWs, we primarily defined two main HAWA subtypes: Perennial HAWA (HAWAP) and temporal HAWA $\left(\mathrm{HAWA}_{\mathrm{T}}\right)$. The differentiation is based on the link between temporal or perennial PAV and temporal or perennial availability of water. Unlike temporal HAWA, perennial HAWA contain constantly high fractions of PAV within a hydrological year starting 1 June and ending at 31 May.

HAWA $_{P}$ have been described in literature as minerotrophic biotopes containing parts of dense cushion-like vegetation cover interrupted by pools and superficial rivulets

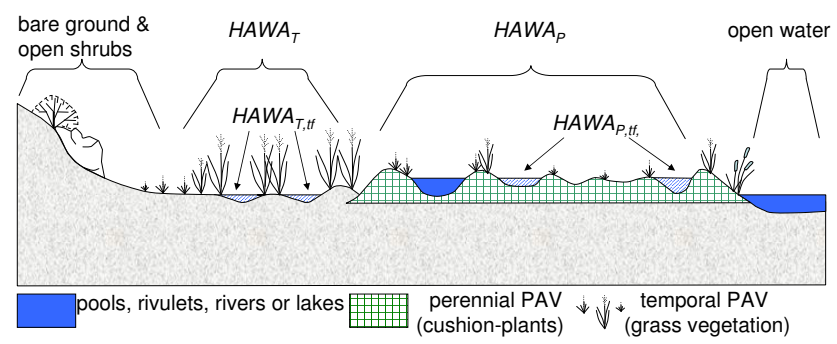

Fig. 2. Schematic cross-cut through an ideal HAWA (modified after Ruthsatz, 2000).

(Ruthsatz, 1993). The Ramsar Convention defines HAWA as inland wetlands that are fed by waters from snowmelt or rain, and as non-forested peatlands, including shrubs, open bogs, swamps and fens (Wetlands International, 2010). TMP defines HAWA as swamps, but without further differentiation to other types of wetlands, for example, coastal wetlands (IAI, 2010).

HAWA vegetation is sometimes compared to Northern Hemisphere peatlands suggesting that peat development can be rapid and extensive, although other plants than Sphagnum sp. are involved (Earle et al., 2003). Most investigations on HAWA provide information on floristic composition based on single sites in Peru, Bolivia, Chile and Argentina (Ruthsatz, 1993, 2000).

Figure 2 depicts a schematic cross-cut view of an ideal HAWA site. Dense PAV cover within HAWAP could consist of cushion-plants interrupted by shallow pools, small puddles or rivulets depending on climatologic conditions that are spatially or temporarily variable (Coronel et al., 2004). HAWA can be situated along rivers, lakes (open water in Fig. 2) or below springs (spring water mire) and gradually or abruptly change from perennially dense cover of PAV (HAWAP) to vegetation of just temporarily high fractions of PAV $\left(\mathrm{HAWA}_{\mathrm{T}}\right)$. HAWA sites can be surrounded by either grasslands, open shrubs or bare grounds.

Figure 3 depicts different HAWA sites within the study region at the end of austral winter (September 2006). Vegetation and water surface cover can be different from site to site ranging from typical dense cushion-plant cover interrupted by pools or rivulets (Fig. 3 top right and lower left) to totally dried out sites containing annual grasses (Fig. 3 top right). Dense cushion-plant cover of HAWA sites depends on hydrologic conditions allowing constant water surplus and, therefore, are limited to areas, for example, valley bottoms of constant river discharge as depicted in Fig. 3 top left and lower right (Ruthsatz, 1993). Cushion-plant dominated HAWA parts are also known as Bofedales containing over 60 plant species with short grasses and dwarf reeds from few millimetres to few centimetres tall (Moreau et al., 2003). Within Bofedales, species of the Juncaceae Oxchloe andina or Distichia muscoides and Patosia clandestina can be found at their whole geographic range forming extensive perennial 

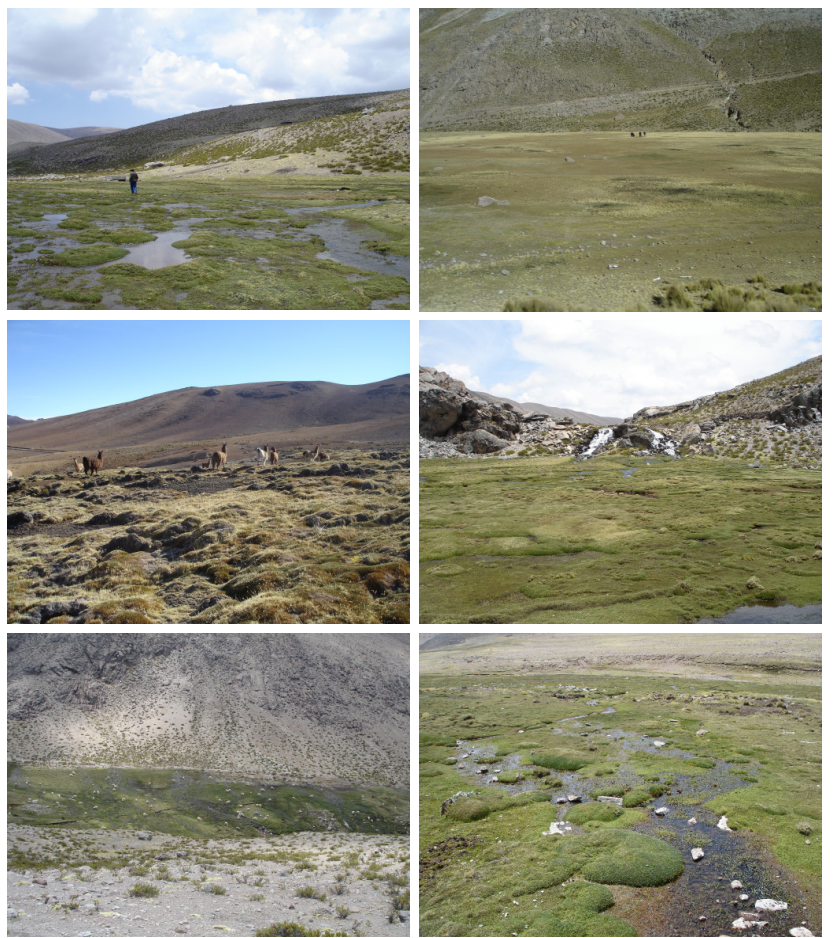

Fig. 3. Photos taken from different HAWA sites at the end of the dry season in 2006. Top left: dense cushion-plant cover of HAWA. Top right: Dried out HAWA site only containing small fractions of cushion-plant cover. Middle left: HAWA site in about $5000 \mathrm{~m}$ a.s.1. Middle right: HAWA site containing dense cushion-plant cover right in front of a small cascade. Lower left: same site as lower right, but photographed from elevated position, note contrast between dense cushion-plant cover and surrounding bare ground or shrub cover (small white dots within HAWA site indicate a grazing alpaca-herd).

vegetation covers within Andean grasslands or shrublands (Ruthsatz, 2000).

Dense cushion-plant cover of HAWAP can also influence local hydrologic conditions through changing water flow paths and discharge velocity. As, an example, Fig. 3 (middle right) shows a HAWA site in front of a small cascade meandering into the green and dense cushion-plant cover. Within HAWA $_{P}$ there are areas of temporal water oversaturated conditions (e.g., Fig. 3 top left) forming shallow pools, rivulets or even flooded areas (Coronel et al., 2004). These parts we refer to as temporarily flooded HAWA $\left(\mathrm{HAWA}_{\mathrm{P}, \mathrm{tf}}\right.$ ) within

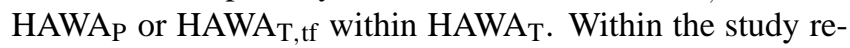
gion HAWA appear between $4000 \mathrm{~m}$ a.s.l. and $5000 \mathrm{~m}$ a.s.l. Figure 3 middle left depicts HAWA site at about $5000 \mathrm{~m}$ a.s.l.
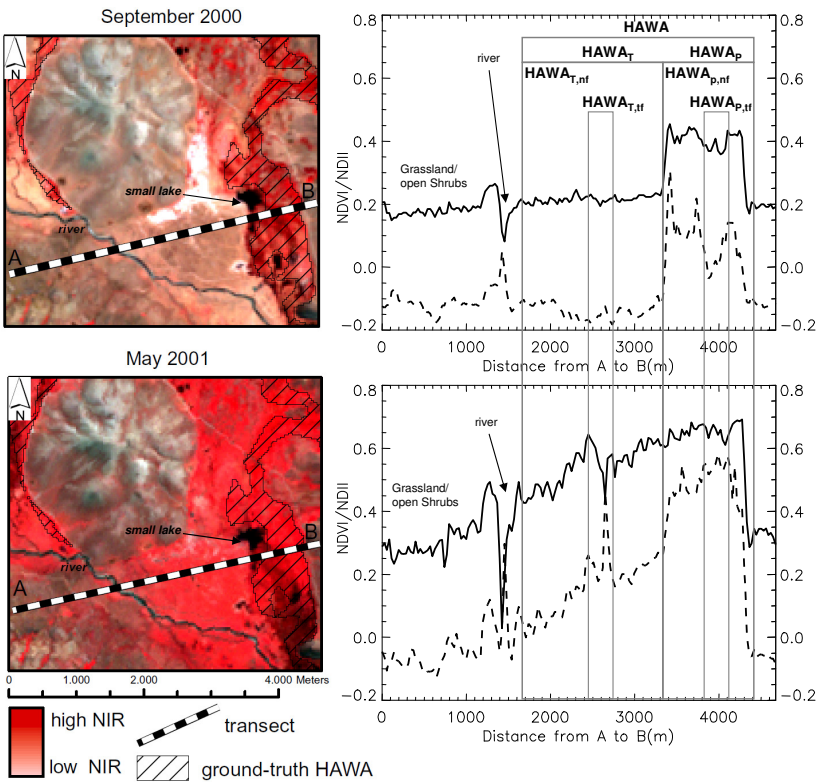

Fig. 4. Left side Landsat ETM+ image in false colour mode (band order 4, 3, 2 in RGB) of ground-truth site upper River Coater (left side) together with corresponding NDVI (solid line) and NDII (dashed line) transects (diagrams on the right side) of September 2000 (above) and May 2001 (below). Grey frames within in the diagrams indicate different HAWA subclasses as described in the text.

\subsubsection{Development of the HAWA mapping procedure}

The transformation of HAWA subtypes into HAWA subclasses utilizing remote-sensing data was the main task of the HAWA mapping procedure (Fig. 4). The HAWA mapping procedure incorporated a classification method in a stepwise manner. A variety of classification methods for remotesensing data exist ranging from visual interpretation over unsupervised and supervised classifiers to more sophisticated methods involving principal component analysis, neural networks or fuzzy logic approaches. The more sophisticated methods have the advantage of handling complex relations between classes. Their major disadvantage is that they require substantial expertise and human interaction to fully utilize their potentials. Decision Tree classifier (DT) have many of the advantages of the sophisticated methods but are much easier to use (Friedl and Brodley, 1997).

Therefore, a supervised multi-temporal mapping procedure based on hierarchical structured binary DT was applied for this study. The structure of a DT classifier consists of a root node, intermediates and terminal nodes separating data based on a set of decision rules. The decision rules were compromised of a set of spectral index thresholds derived from ground-truth data in order to separate HAWA land cover from other land covers and then differentiate HAWA land cover into subclasses following the developed HAWA mapping design. In the first step of the mapping procedure, DT 
classifiers were used to differentiate between HAWA and other land cover classes once for the austral winter data of 2000 and again for austral summer data in 2001. For this purpose, a general land cover scheme similar to the land cover scheme used by the International Geosphere-Biosphere Program (IGBP) was applied and consists of four main natural vegetation classes (Loveland et al., 2000): (1) Wetlands (HAWA), (2) Grasslands (Gra), (3) Shrublands (Shr), (4) Barren or Sparsely vegetated (B \& S). Secondly, a DT classifier was used to separate the four HAWA subclasses from each others incorporating land cover status of wet season (September 2000) and dry season (May 2001). Finally, thresholds derived from the relationship between NDII and NDVI were applied to derive temporarily flooded HAWA subclasses.

Formal accuracy assessment was performed based on the ground-truth test site data of each land cover class calculating overall and class-specific accuracies, Kappa Coefficients, errors of commission and omission, as well as user and producer accuracies. Data derived from HAWA test sites used for accuracy assessment were not included in derivation of vegetation index thresholds incorporated as decision rules into the DT classifier.

\subsubsection{Annual HAWA mapping and applied precipitation data}

The second objective of the study was focused on hydrological differentiation of HAWA and HAWA subtypes regarding precipitation as a main driving factor within semi-arid climates. After assessment of MODIS based HAWA mapping for the year 2000 to 2001, a time series of annual HAWA land cover was computed utilizing MODIS 16 day NDVI composites at spatial resolution of $250 \mathrm{~m}$ (MOD13Q1) from 2000 to 2001 (00_01) to 2009 to 2010 (09_10). The MOD13Q1 product has the advantage of combining best NDVI estimates over a 16 day time period reducing negative impacts on data quality by, e.g., clouds (Huete et al., 2002).

The data pre-processing for the annual HAWA mapping consists of two main steps. First, we derived NDVI thresholds based on HAWA $(\mathrm{gt})$ from MOD13Q1 composites of 2000 to 2001 which we then implemented into the HAWA mapping procedure for all years. Second, annual land cover proportions (in \%) of HAWA $\mathrm{P}$ and $\mathrm{HAWA}_{\mathrm{T}}$ were computed from 2000 to 2010. To evaluate the relations found between HAWA and precipitation, we computed the ratio $\left(R \mathrm{HAWA}_{\mathrm{P} / \mathrm{T}}\right)$ between the annual proportions covered by the two main HAWA subclasses as follows:

$R \mathrm{HAWA}_{\mathrm{P}} \mathrm{T}=\frac{\text { HAWA }_{\mathrm{P}}}{\mathrm{HAWA}_{\mathrm{T}}}$.

$R$ HAWA $_{\mathrm{P} / \mathrm{T}}$ should be sensitive to changes in land cover proportions of each HAWA subclass. In some years when, for example, snow cover proportion was less than in other years land cover proportion of the HAWA subclass which depends stronger on snow cover could be decreased resulting in a different $R \mathrm{HAWA}_{\mathrm{P} / \mathrm{T}}$.

In order to investigate relations between changes in land cover proportion of HAWA and precipitation, three-monthly means of precipitation and snow cover time series were correlated computing Pearson's correlation coefficients and regressions. Three-monthly mean precipitation rates were derived from monthly precipitation data of the Tropical Rain Measurement Mission (TRMM-3B43) and ten years of snow cover data was derived from MODIS Eight Day Maximum Snow Extend data (MOD10A2) and converted into three-monthly average snow cover data. All MODIS datasets were downloaded via The Warehouse Inventory Search Tool (WIST) provided by National Aeronautics and Space Administration (NASA). Three-monthly mean precipitation rates of TRMM-3B43 data were downloaded using the Giovanni online data system (http://disc2.nascom.nasa. gov/Giovanni/tovas/).

\section{Results}

\subsection{HAWA mapping design}

The characteristics of HAWA subtypes had to be transformed into HAWA subclasses following the HAWA mapping design. The HAWA mapping design was the conceptual frame for the HAWA mapping procedure which was applied for both HAWA mappings utilizing first Landsat ETM+ and secondly MODIS datasets. Figure 4 depicts an example of a HAWA site and its surroundings in false colour mode from Landsat ETM+ of September 2000 (top left) and May 2001 (lower left) together with corresponding NDVI and NDII values along the black and white marked transect (Fig. 4 right). Dashed areas in Fig. 4 (left) indicate parts of one of the ground-truth sites (upper River Coata). Also parts of the upper tributary of the River Coata can be identified as grey winding line south and south-west of the ground-truth site. Note the remarkable change in the red tone (high reflectance values in $\rho_{\text {NIR }}$ ) which corresponds to changes of spectral indices (Fig. 4 right) of the transect part between the river and the eastern ground-truth site in September 2000 compared to May 2001.

Grey frames in the diagrams of Fig. 4 (right) indicate different HAWA subtypes. The outer frame marks the part of the transect crossing the HAWA site. The larger left frame within the HAWA part indicates temporal HAWA $\left(\mathrm{HAWA}_{\mathrm{T}}\right)$ because both vegetation indices show higher temporal variation compared to the part crossing perennial HAWA (HAWA $)$ which is marked by the smaller right frame in the diagrams of Fig. 4. Within $\mathrm{HAWA}_{\mathrm{T}}$ and $\mathrm{HAWA}_{P}$ there are areas (small grey frames in Fig. 4) identified as

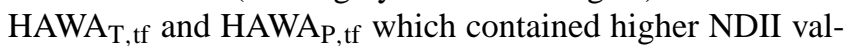
ues in May 2001. Since the NDII reflects high proportion of water surface and plant water content $\mathrm{HAWA}_{\mathrm{T}, \mathrm{tf}}$ 
Table 1. Three assumptions (1st-3rd) made based on characteristics in vegetation and hydrologic conditions of HAWA subtypes and derived HAWA subclasses for HAWA mapping based on satellite data as shown in Fig. 4 and introduce into the HAWA-mapping design (Fig. 5). Bold and case-sensitive letters indicate the link between the characteristics of HAWA subtypes and abbreviations used for the HAWA subclasses.

\begin{tabular}{|c|c|c|c|c|c|}
\hline $1 \mathrm{st}$ & 2 nd & $3 \mathrm{rd}$ & & & \\
\hline HAWA & HAWA subtypes & Hydrology & Vegetation & $\begin{array}{l}\text { Spectral } \\
\text { indexes }\end{array}$ & $\begin{array}{l}\text { HAWA } \\
\text { subclasses }\end{array}$ \\
\hline \multirow{4}{*}{$\begin{array}{l}\text { containing } \\
\text { highest PAV } \\
\text { compared to } \\
\text { other land } \\
\text { cover types in } \\
\text { the Puna } \\
\text { (>4000 m a.s.l.) }\end{array}$} & \multirow{2}{*}{$\begin{array}{l}\text { dense vegetation cover } \\
\text { of Perennial water } \\
\text { surplus and Perennially } \\
\text { highest fraction of PAV }\end{array}$} & $\begin{array}{l}\text { Perennial water surplus } \\
\text { non flooded }\end{array}$ & \multirow{2}{*}{ cushion-plants } & $\begin{array}{l}\text { Perennially } \\
\text { highest NDVI }\end{array}$ & $\begin{array}{l}\text { HAWAP }_{\mathbf{P}} \\
\text { HAWA } \mathbf{P , n f}\end{array}$ \\
\hline & & $\begin{array}{l}\text { Perennial water surplus } \\
\text { temporarily flooded }\end{array}$ & & $\begin{array}{l}\text { Perennially } \\
\text { highest NDVI } \\
\text { Temporarily } \\
\text { highest NDII } \\
\end{array}$ & HAWA $_{\mathbf{P , t f}}$ \\
\hline & \multirow{2}{*}{$\begin{array}{l}\text { annual vegetation cover } \\
\text { of temporal water } \\
\text { surplus and temporarily } \\
\text { highest fraction of PAV }\end{array}$} & $\begin{array}{l}\text { temporal water surplus } \\
\text { non flooded }\end{array}$ & \multirow{2}{*}{$\begin{array}{l}\text { annual grass } \\
\text { vegetation }\end{array}$} & $\begin{array}{l}\text { Temporal } \\
\text { highest NDVI }\end{array}$ & $\begin{array}{l}\mathrm{HAWA}_{\mathbf{T}} \\
\text { HAWA }_{\mathbf{T}, \mathbf{n f}}\end{array}$ \\
\hline & & $\begin{array}{l}\text { temporal water surplus } \\
\text { temporarily } \\
\text { flooded }\end{array}$ & & $\begin{array}{l}\text { Temporarily } \\
\text { highest } \\
\text { NDVI/NDII }\end{array}$ & $\mathrm{HAWA}_{\mathbf{T , t f}}$ \\
\hline
\end{tabular}

and HAWA Hf $_{\text {,f }}$ are referred to as temporarily flooded areas within HAWA. Non-flooded areas are referred to as

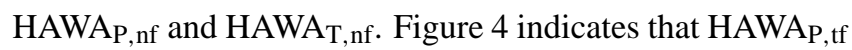
contained greater NDII variance compared to $\mathrm{HAWA}_{\mathrm{P}, \mathrm{nf}}$ between September 2000 (below zero) and May 2001.

Following the information found in literature and the results of the analyses conducted on ground-truth data HAWA subtypes can be transformed into HAWA subclasses by a one-to-one translation of the three assumptions (1st-3rd) shown in Table 1 (columns 1 to 4 ) to develop the HAWA mapping design as illustrated in Fig. 5. The HAWA land cover class contains highest NDVI values compared to other land cover types in the Puna region during the year (1st). The HAWA vegetation cover represents different temporal dynamics of PAV and, therefore, can be divided into two

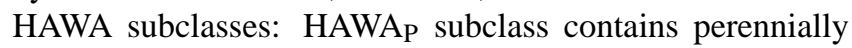
highest NDVI values and $\mathrm{HAWA}_{\mathrm{T}}$ subclass contains temporarily highest NDVI values only after raining season in austral summer (2nd). HAWA and HAWA $_{T}$ could contain flooded parts representing temporarily higher NDII values

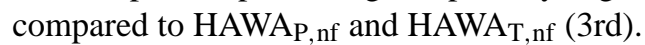

After development of the HAWA mapping design, defining HAWA subtypes and transforming them into HAWA subclasses, NDVI and NDII thresholds had to be derived based on ground-truth data. Index thresholds were implemented via the DT classifiers within the HAWA mapping procedure (Fig. 4 in Appendix A) following the hierarchical structure of the HAWA mapping design. Figure 6 depicts box plots derived from ground-truth (gt) grid elements of each land cover class of September 2000 (upper left) and May 2001 (upper right). Numbers on top and below the single boxes in Fig. 6 indicate NDVI thresholds at $P_{95 \%}$ and $P_{5 \%}$ as derived from

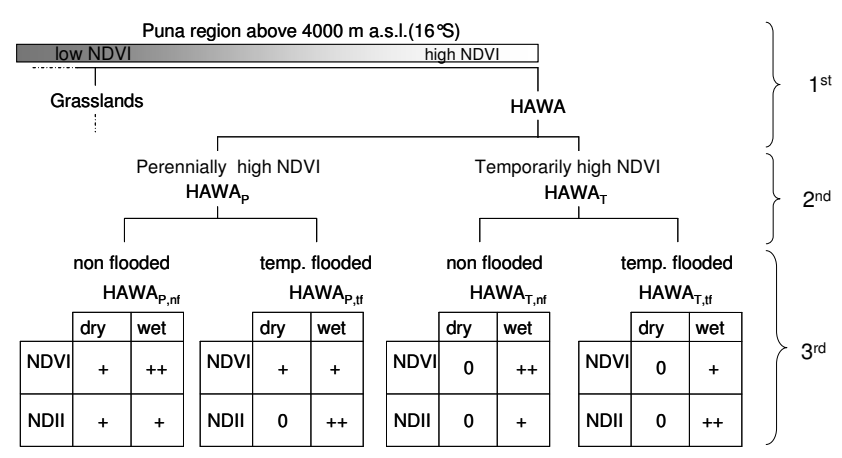

Fig. 5. HAWA mapping design for the use of remote-sensing techniques transforming HAWA subtypes into HAWA subclasses.

the ground-truth (gt) data based on Landsat ETM+. Within each box plot additionally relative frequency distribution of NDVI values for the entire study region are shown indicating that NDVI range of HAWA $\left(P_{5 \%}-P_{95 \%}\right)$ is represented in the flat-tailed part of the distribution (e.g., for September 2000: 0.27 NDVI to 0.6 NDVI). HAWA(gt) contained highest NDVI values up to 0.74 and greatest NDVI range in May 2001 (0.31). Minimum NDVI value for HAWA(gt) was below NDVI $P_{5 \%}$ of Gra(gt) in May 2001, indicating water saturated conditions or false selected ground-truth grid elements. Figure 6 also depicts that $P_{5 \%}$ of B \& S(gt), Gra (gt) and $\operatorname{Shr}(\mathrm{gt})$ were close together or even slightly overlapping. $P_{5 \%}$ of HAWA $(\mathrm{gt})$ indicated greater distance to the closest land cover class $\left(P_{95} \%\right.$ of $\left.\mathrm{Gra}(\mathrm{gt})\right)$ in September 2000 and May 2001. NDVI percentiles of $\mathrm{B} \& \mathrm{~S}(\mathrm{gt})$ did not vary as much as other land cover classes and, hence, represented lowest content of vegetation in September 2000 as well as in May 2001. 

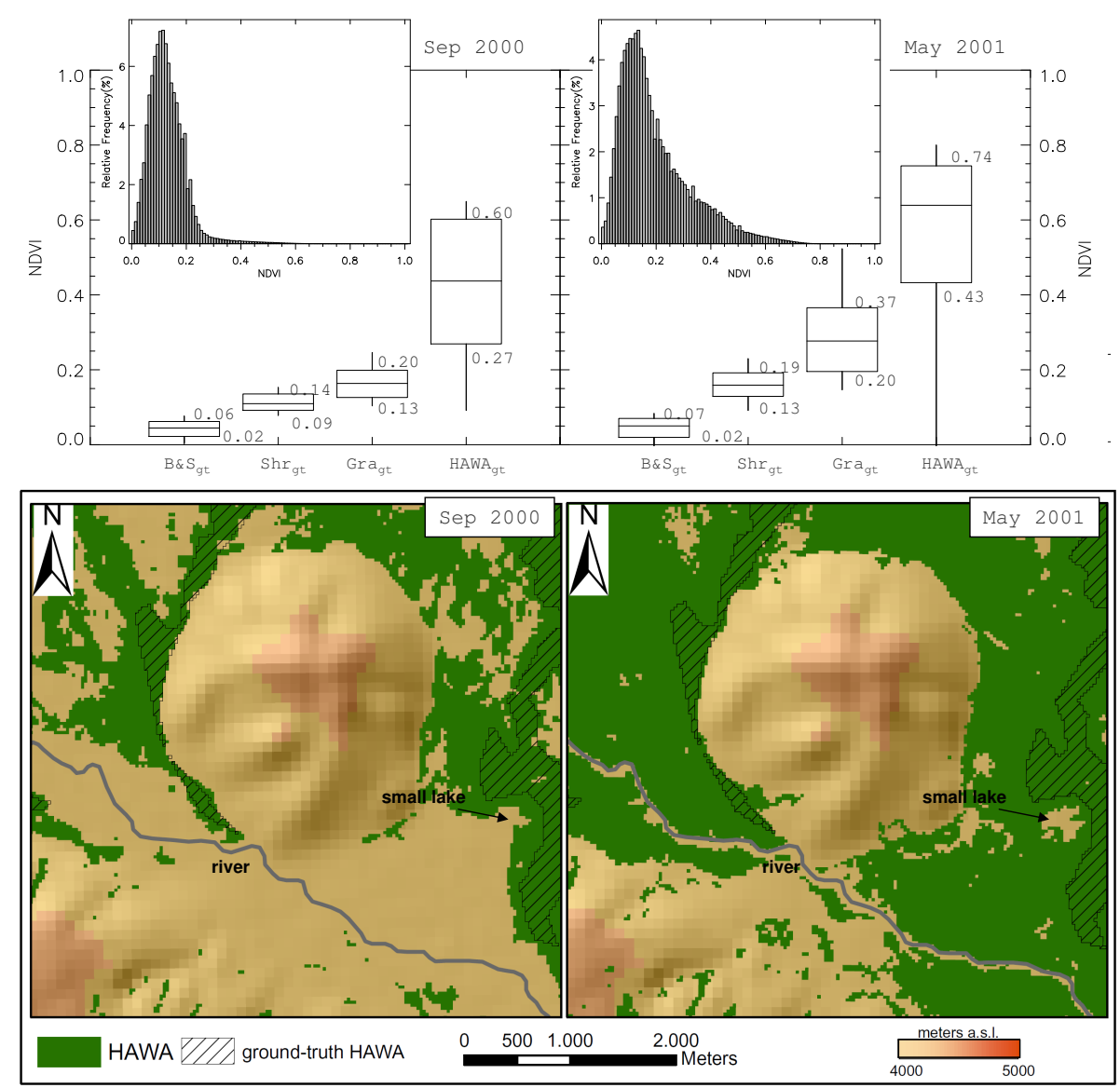

Fig. 6. Box plots (upper part) of five hundred stratified randomly sampled grid values for each ground-truth dataset of September 2000 and May 2001. Box range is set to P5 \% and P95 \% together with median and maximum/minimum grid values for each land cover class. Lower part of Fig. 5 depicts HAWA mapped in September 2000 and May 2001 applying thresholds as depicted in the respective box plots (upper part).

As depicted in Fig. 6 the $P_{5 \%}$ of each land cover groundtruth NDVI dataset were applied as thresholds separating each land cover from the lower neighbouring land cover class. Except for September 2000 (Fig. 6 upper left) where lower percentile of Grassland $\left(P_{5 \%}\right)$ was slightly overlapping the upper percentile $\left(P_{95 \%}\right)$ of $\operatorname{Shr}(\mathrm{gt})$. Since the focus was on mapping HAWA, we just applied the upper percentile $\left(P_{95 \%}\right)$ to separate $\mathrm{Shr}$ from Gra land cover. Since this is not the case for May 2001, the $P_{5 \%}$ threshold of Gra(gt) was applied. B \& S (gt) shows only small changes in $P_{95} \%$ due to low vegetation content. Therefore, $P_{95 \%}$ was applied as threshold for mapping of Shr in September 2000 as well as in May 2001. $P_{5} \%$ of B \& S(gt) was used to separate B \& S. All values below $P_{5} \%$ of B \& S(gt) are not classified. Figure 6 (lower part) depicts a subset of the HAWA mapping result (same subset as in Fig. 4) after applying NDVI thresholds as decision rules to the DT classifier for September 2000 (Fig. 5 lower left) and May 2001 (Fig. 5 lower right). As a result area of HAWA site mapped in September 2000 has almost doubled in May 2001, due to the fact that some HAWA parts changed from e.g., Grassland in September 2000 to HAWA in May 2001. The HAWA mapping results of September 2000 and May 2001 based on Landsat ETM+ have class specific accuracies of above $90 \%$ for all land covers resulting in a high overall accuracy of $93 \%$ in September 2000 and $94 \%$ in May 2001. Kappa Coefficients are very high and, hence, accuracy statistics are very good for both HAWA mapping results. Percentage of User Accuracy is $100 \%$ for both mapping results which indicates a very high probability that HAWA test site data represent HAWA land cover class. One has to consider that all HAWA test sites were independent because they were not incorporated into NDVI threshold derivation for the DT classifier.

Note that in Fig. 6 (right) almost the entire area between the river and the ground-truth HAWA site were classified as HAWA in May 2001. These areas were mapped as HAWA subclass applying a second DT classifier for the final HAWA mapping result. With the above described first two steps of HAWA mapping we could first, separate HAWA from other land cover classes and secondly, HAWA land cover class

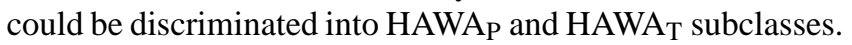


In a third step, a threshold has to be derived based on NDVI and NDII relationship to discriminate between flooded and non-flooded HAWA parts defined as $\mathrm{HAWA}_{\mathrm{P}, \mathrm{nf}}$ and

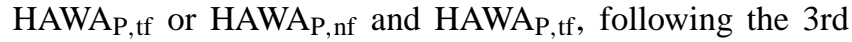
assumption of the HAWA mapping design (Fig. 5). NDVI and NDII are normalized indices enabling comparison of different land covers and also comparison of the indices themselves. NDVI and NDII represent vegetation cover through high reflectance in $\rho_{\mathrm{NIR}}$. NDII also represents plant water content or water saturated conditions (flooding) through differential sensitivity of $\rho_{\text {NIR }}$ and $\rho_{\text {SWIR }}$ caused by radiative characteristics of water within this range of the electromagnetic spectrum (Tucker, 1979). Areas of dense vegetation cover are represented by high NDVI values. The abscissa in Fig. 7 (top) represents NDVI between 0 and 1. An increasing NDVI value is a result of increasing PAV cover. In return, areas of open water usually found within $\mathrm{HAWA}_{\mathrm{P}, \mathrm{tf}}$ and HAWA $_{\text {, tf }}$ decrease proportion of PAV cover causing lingering or decreasing NDVI values, but increasing NDII values (along the ordinate in Fig. 7). Based on this relation NDII pixel values of HAWA land cover were evenly clustered into 0.1 intervals. Then statistics of corresponding HAWA NDVI grid elements were computed for each $0.1 \mathrm{NDII}$ interval to determine the NDII threshold used for mapping of HAWA ,tf $_{\text {,f }}$ and $\mathrm{HAWA}_{\mathrm{T}, \mathrm{ff}}$. As depicted in Fig. 7 each NDII interval is represented by a box of 0.1 NDII units. Upper and lower boxborders mark $P_{10 \%}$ and $P_{90 \%}$, respectively, for all mapped HAWA NDVI grid element values found within their corresponding $0.1 \mathrm{NDII}$ interval. Horizontal bold lines within the small boxes represent the median NDVI. NDII interval of 0.45 to 0.55 represents highest median NDVI. At this interval HAWA NDII values still increase and NDVI retains or decreases due to the effect of increasing water and decreasing PAV cover (as also depicted in Fig. 4). Finally the NDII threshold of 0.45 (red dotted line in Fig. 7 bottom) was applied to differentiate between HAWA $_{P, \text { tf }}$ and HAWA $_{P, n f}$ as well as $\mathrm{HAWA}_{\mathrm{T}, \mathrm{ff}}$ and $\mathrm{HAWA}_{\mathrm{T}, \mathrm{nf}}$.

\subsection{HAWA mapping results}

The total mapped area covers approximately $12800 \mathrm{~km}^{2}$. Accuracy assessment of the final Landsat ETM+ based HAWA mapping result indicates high overall accuracy of $93 \%$ with very good class specific accuracies for HAWA land cover class $(97 \%)$. Therefore, HAWA mapping error is about 3\% applying Landsat ETM+. The area covered by HAWA is about $6 \%$ (approximately $800 \mathrm{~km}^{2}$, $\pm 12 \mathrm{~km}^{2}$ mapping error) whereby $50 \%$ of the HAWA area consists of HAWA ${ }_{P}$ and about $50 \%$ consists of HAWA subclasses. Total cover of temporarily flooded HAWA subclasses (HAWA $_{\mathrm{P}, \mathrm{tf}}$ and $\mathrm{HAWA}_{\mathrm{T}, \mathrm{tf}}$ ) is less then $1 \%$ $\left(120 \mathrm{~km}^{2}\right)$. Grasslands (Gra) cover $35 \%\left(4500 \mathrm{~km}^{2}\right)$, Shrublands (Shr) about $39 \%\left(5000 \mathrm{~km}^{2}\right)$ and Barren or Sparsely vegetated soils $(\mathrm{B} \& \mathrm{~S})$ cover $5 \%\left(800 \mathrm{~km}^{2}\right)$. About $15 \%$
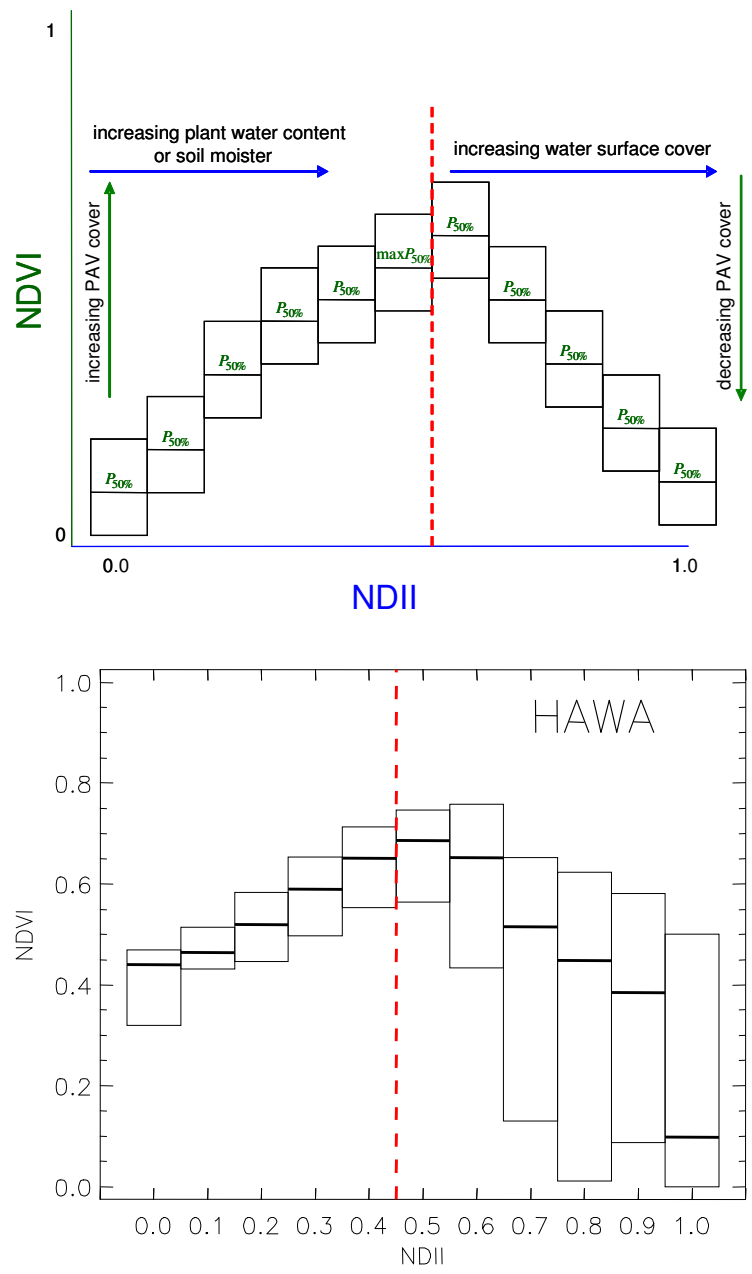

Fig. 7. Schematic representation of NDVI and NDII relations (top) and derivation of NDII threshold for HAWA, tf computing NDVI statistics at 0.1 NDII intervals (bottom).

$\left(1800 \mathrm{~km}^{2}\right)$ where not classified (below $4000 \mathrm{~m}$ a.s.l., lakes urban areas or shadowed areas).

HAWA land cover is not equally distributed within the study region. Most HAWA sites are situated in the northern parts of the study region. Figure 8 depicts three examples of HAWA sites from the northern part (Fig. 8, left), central part (Fig. 8, centre) and the southern part (Fig. 8, right) of the study region. Dashed parts within Fig. 8 represent HAWA sites and different HAWA subtypes are represented by different colours. Upper River Coata site (subset in Fig. 8 left, also Figs. 4 and 6) contains large distinctive areas of HAWA $_{P}$ (in total about $48 \mathrm{~km}^{2}$ ) and HAWA (in total about $58 \mathrm{~km}^{2}$ ). Hence, upper River Coata ground-truth site is one of the largest HAWA sites $\left(109 \mathrm{~km}^{2}\right)$ within the study region. The upper River Coata basin has a total size of approximately $460 \mathrm{~km}^{2}$ (information derived from DTM) and is situated within the moist Puna belt. About $23 \%\left(109 \mathrm{~km}^{2}\right)$ is covered by HAWA. This is about three times higher compared to total 
Table 2. Comparison of HAWA land cover and HAWA subtype cover mapped using Landsat ETM+ and MODIS data in a $2 \times 2$ contingency table. Bold numbers refer to total cover of HAWA and HAWA subclasses for each HAWA mapping result.

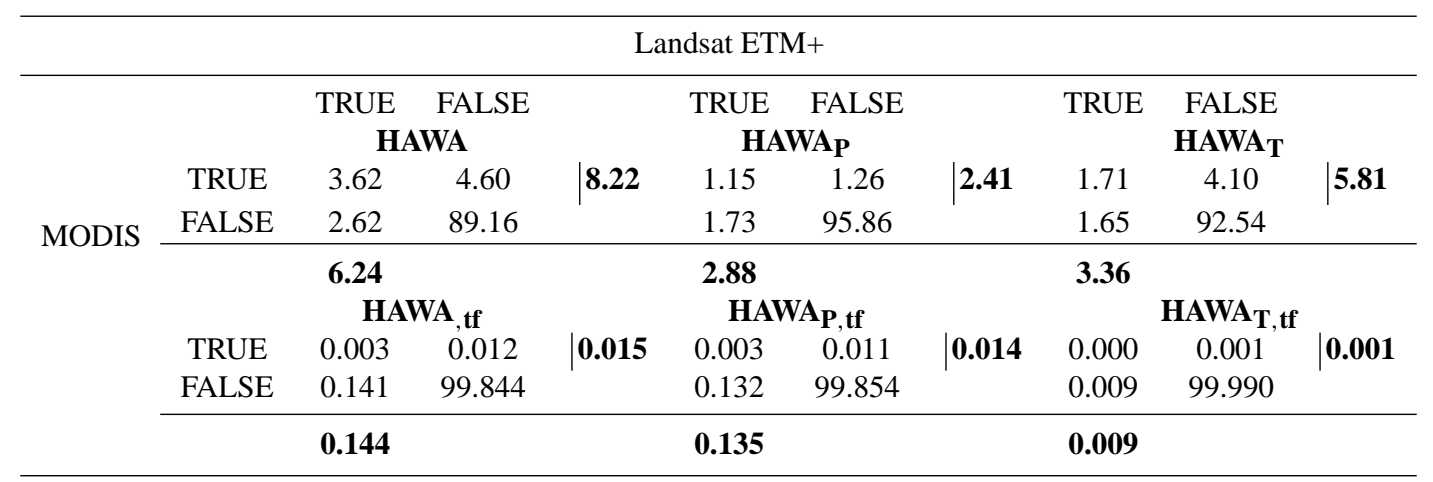
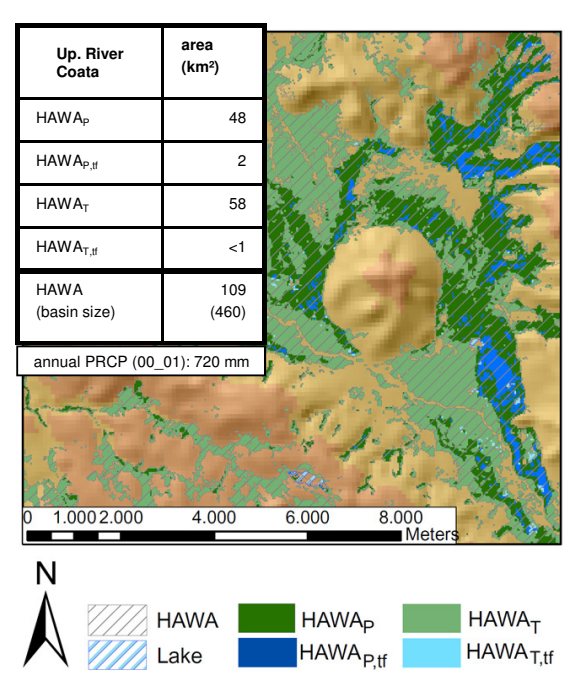
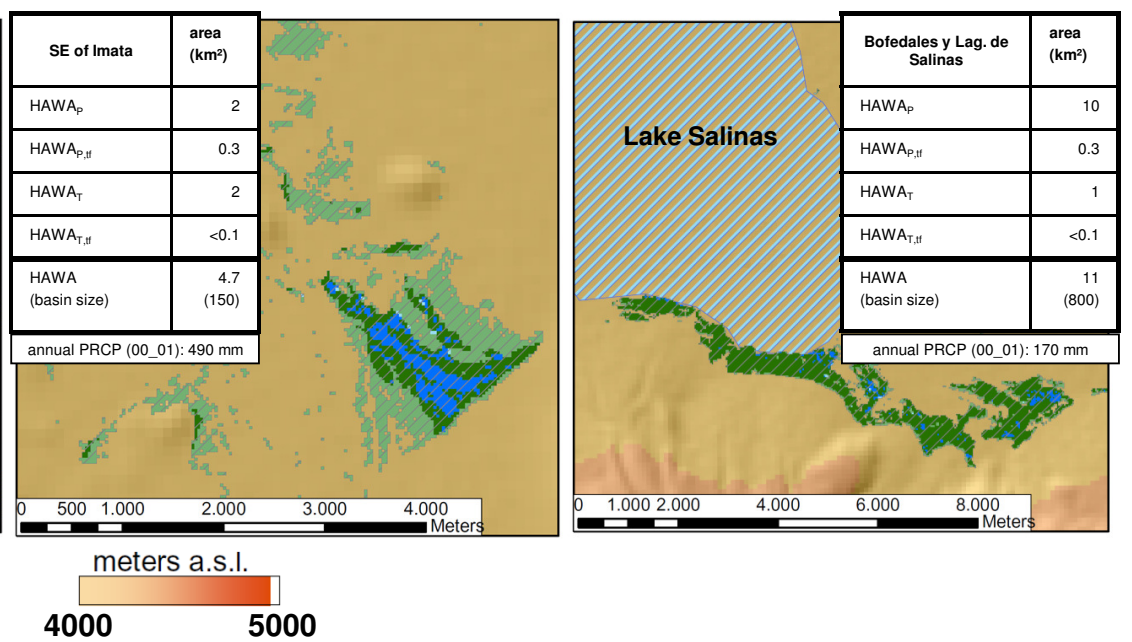

Fig. 8. Subsets of Landsat ETM+ based HAWA mapping result (only HAWA). Left: Upper River Coater, centre: South East of the village Imata, right: HAWA area of Ramsar Site Bofedales y Laguna de Salinas (Ramsar Site NO.: 1317). Numbers in attached tables indicate total cover of HAWA subtypes within corresponding basins (number top left of each table) and annual precipitation rates (annual PRCP).

HAWA cover $(6 \%)$ of the entire study region. HAWA H $_{\text {,tf }}$ and $\mathrm{HAWA}_{\mathrm{T} \text {,ff }}$ cover smallest area. HAWA ${ }_{\mathrm{P}, \mathrm{ff}}$ at upper River Coata site cover $4 \%$ (about $2 \mathrm{~km}^{2}$ ) of HAWAP area which is higher compared to total HAWA $_{P, t f}$ cover of the entire study region (less then $1 \%$ ). This is also true to HAWA $\mathrm{T}_{\mathrm{T}, \mathrm{tf}}$ covering $2 \%$ of HAWA ${ }_{\mathrm{T}}$ of River Coata site. The HAWA site southeast of Imata (Fig. 8, middle also in Fig. 1c) is of $5 \mathrm{~km}^{2}$ spatial size but contains high percentage of HAWAP,tf (15\%). Ramsar site Bofedales y Laguna de Salina (Fig. 8 right, close to Lake Salinas in Fig. 1c) is situated in the dry Puna belt and consists of about $10 \mathrm{~km}^{2}$ of HAWA and about $1 \mathrm{~km}^{2}$ of $\mathrm{HAWA}_{\mathrm{T}}$.

In order to monitor spatial changes of HAWA, data of better time consistency is needed. NDVI data of MODIS (MOD13Q1) is based on daily observations and contain more than 10 years of ready to use global NDVI measurements free available via the Internet (Huete et al., 2002). MODIS based
NDVI measurements might have great potential for HAWA mapping and monitoring. Therefore, we first applied the developed HAWA mapping procedure also to MODIS NDVI data derived from surface reflectance data sets (MOD09 and MOD02) of the same time periods. MODIS and Landsat ETM+ have different spatial and spectral characteristics. For this reason potential for continuous monitoring of HAWA applying MODIS data was quantitatively assessed in a second step. As a result a $2 \times 2$ contingency table was computed for HAWA land cover and HAWA subclasses (Table 2) for the entire study region. The numbers in Table 2 refer to area coverage in percent of total area mapped in the study region. Bold numbers in Table 2 refer to total cover of HAWA land cover class and HAWA subclass, respectively, for each HAWA mapping result. For HAWA land cover class $3.62 \%$ of the study region was mapped (TRUE in Table 2) in both HAWA mapping results. On the contrary $89.19 \%$ of 


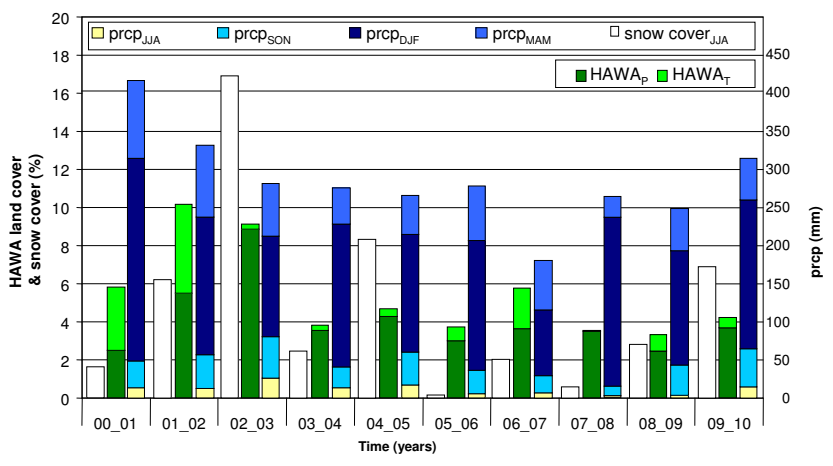

Fig. 9. Annual time series of MODIS based HAWAP and HAWA land cover, three-monthly precipitation $(\mathrm{mm})$ derived from monthly rain rate of TRMM (3B43) from 1 June 2000 to 31 May 2001 (00_01) till 1 June 2009 to 31 May 2010 (09_10) and average threemonthly (JJA) snow cover (JJA) based on MODIS Eight Day Maximum Snow Extend data (MOD10A2).

the study region was not mapped as HAWA in either Landsat ETM+ based nor MODIS based HAWA mapping (FALSE in Table 2). If we consider Landsat ETM+ based HAWA mapping as the ground-truth dataset then $6.24 \%$ of the study region is covered by HAWA land cover class whereby $2.62 \%$ of the HAWA site was not mapped using MODIS. Instead $4.6 \%$ of the study region was mapped as HAWA only in the MODIS based HAWA mapping. Therefore, we can conclude that first, about two thirds (3.62\% TRUE in both) of Landsat ETM+ based HAWA mapping $(6.24 \%$ total HAWA, bold number in Table 2) are also mapped using MODIS. Secondly, that MODIS overestimates HAWA site resulting in a total HAWA land cover area of $8.22 \%$ (bold number in Table 2) which is about $2 \%$ higher then total HAWA land cover area mapped using Landsat ETM+. As shown in Table 2 overestimation primarily occurs in $\mathrm{HAWA}_{\mathrm{T}}$ subclass because percentage of HAWA $_{\mathrm{T}}$ area only mapped in MODIS (4.1\%) is almost equal to the overestimated HAWA area (4.6\%).

Quantitative assessment of HAWA ${ }_{P, t f}$ subclasses indicate that only very small fractions were mapped using MODIS. This is due to the general small percentage of land cover containing HAWA $_{P, \text { tf }}$ subclasses already in the Landsat ETM+ HAWA mapping result. Therefore, respective numbers in Table 2 are below significance and were not considered for further time series analysis applying MODIS-NDVI data (MOD13Q1).

\subsection{Hydrological differentiation of HAWA}

Taking in mind that MODIS based HAWA mapping is still feasible even at coarser spatial resolution a land cover map based on MOD13Q1 data was produced applying NDVI thresholds derived from the year 2000 to 2001 (00_01). Hence, the mapping criterion was left unchanged for each year $\left(00 \_01\right.$ to $\left.09 \_10\right)$ to analyse spatial changes of areas that reached at least the same level of PAV as in 2000 to 2001.

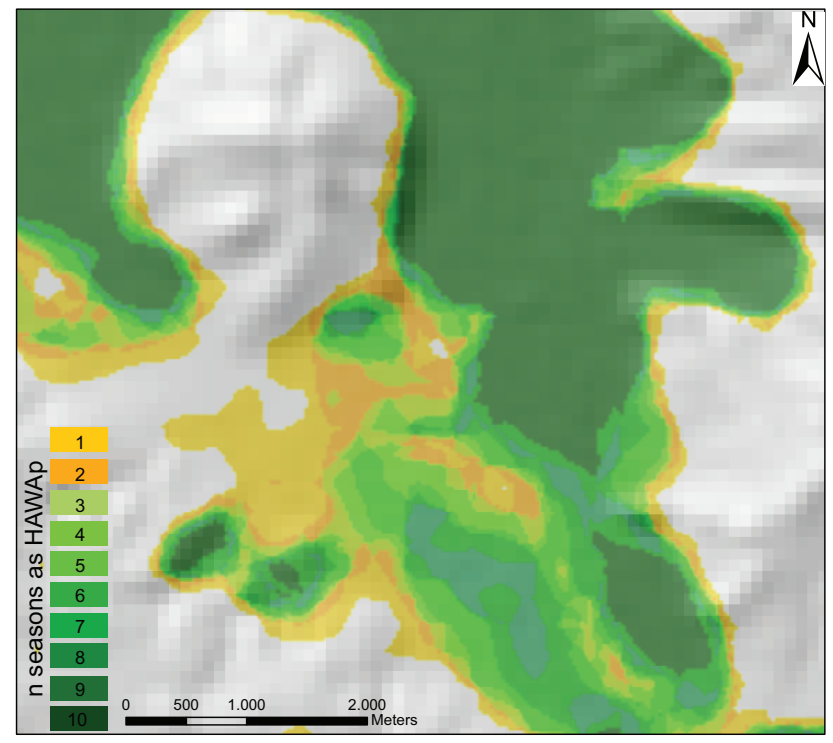

Fig. 10. Annual changes in spatial extend of HAWAP. Numbers in coloured rectangular boxes indicate number of years where areas were mapped as HAWAP.

The question is if HAWAP land cover area defined in 00_01 was always of the same spatial extend. Figure 9 depicts land cover mapped as HAWA subdivided in HAWAP and HAWA indicating that spatial coverage of HAWA varies between $2 \%$ and $4 \%$ for most of the years. But some years indicate higher HAWAP land cover, for example, 01_02 where HAWA $_{P}$ land cover was more than four times higher compared to $\mathrm{HAWA}_{\mathrm{T}}$ land cover. Figure 9 also depicts annual precipitation subdivided into three-monthly precipitation rates (JJA, SON, DJF and MAM) and also percentage of snow cover in austral winter months (snow cover ${ }_{J J A}$ ) for each year. Both annual precipitation as well as three-monthly precipitation and snow cover were highly variable. Annual precipitation amount ranged from more than $400 \mathrm{~mm}$ in $00 \_01$ to less than $200 \mathrm{~mm}$ 06_07. In general temporal distribution of precipitation was relatively constant for the whole time period with most of the precipitation occurring during austral summer (60\% during DJF) and low precipitation amounts during austral winter (4\% in JJA). Snow cover JJA $_{\text {in }}$ in austral winter (six out of ten) was about $2 \%$ or less but was significantly higher in 01_02 (6\%), 02_03 (16\%) and 09_10 (7\%).

Compared to Fig. 10 annual changes in spatial extend of HAWAP $_{P}$ at upper River Coata test site indicate spatial frequency of mapped HAWAP. The numbers in coloured rectangular boxes of Fig. 10 indicate the numbers of years were an area was mapped as HAWAP. For the upper River Coata test site we could, therefore, specify areas constantly mapped as HAWA $_{P}$ (maximum of ten years in Fig. 10 - dark green) and areas which were not constantly mapped as HAWA (minimum of one year in Fig. 10 - yellow) between 2000 and 2010. About $2 \%$ of the whole study region contains 
constantly mapped HAWAP land cover. Hence, the above proposed question could be answered as follows: Not all HAWA $P$ areas mapped in 00_01 were always mapped in the other years. $\mathrm{HAWA}_{\mathrm{T}}$ areas were highly variable ranging from almost 5\% in 01_02 to almost $0 \%$ in 07_08 (0.06\%).

Based on the answer of the above-stated question, we wanted to know if precipitation was a key factor for annual changes of HAWA $P$ and $\mathrm{HAWA}_{\mathrm{T}}$ land cover. Figure $10 \mathrm{de}-$ picts that less constantly mapped HAWA $P$ areas were at a further distance from the more constant ones indicating a spatial gradient (from dark green to yellow in Fig. 10). Compared to Fig. 9 this spatial gradient might be a consequence of absolute and temporal changes in precipitation. Therefore, we analysed the relation between precipitation and HAWA land cover for the entire study region. Figure 11 top depicts the dependency of $\mathrm{HAWA}_{\mathrm{T}}$ land cover to prcpMAM as well as HAWA $_{P}$ land cover and snow cover JJA (Fig. 11 bottom) indicating high correlation coefficients $\left(r^{2}: 0.75\right.$ and $r^{2}: 0.82$, respectively). The highest correlation coefficient was found applying exponential regression for $\mathrm{HAWA}_{\mathrm{T}}$ and linear regression for HAWAP land cover. Correlation coefficients of total annual precipitation (not shown in Fig. 11) and HAWA subclasses were lower (e.g., $r^{2}$ : 0.6 for HAWAP) and correlation coefficient based on other combinations between temporal precipitation means and $\mathrm{HAWA}_{\mathrm{T}}$ or $\mathrm{HAWA}_{\mathrm{P}}$ land cover were below $r^{2}: 0.6$ (e.g., for prcpMAM and HAWAP $-r^{2}: 0.0$ ).

\section{Discussion}

Existing HAWA mappings were of insufficient quality for investigations on HAWA. We used TMP combined with other land cover data for deriving HAWA test sites. TMP has been the most detailed information source regarding distribution of HAWA within the study region (IAI, 2010). About 580 sites were classified as Swamp (Pantano) in TMP covering $590 \mathrm{~km}^{2}$. In general, all ground truth sites and HAWA test sites were represented also in TMP, but were overestimated up to $50 \%$ and only $20 \%$ of all mapped HAWA sites are also mapped in TMP. The number of HAWA sites in TMP is underestimated, but the area at a single HAWA site is often overestimated. The applied methodology of visual interpretation (MULTIPLEX, A-8) based on aerial photos (black \& white) of 1955 conducted in 1964 (IAI, 2010) could be the underlying reason. There was no further information available on data acquisition time and the conducted field work. The updated version of TMP of 1990 showed inconsistencies to the TMP of 1955. We found large sites mapped as swamps appearing only in the updated version of TMP. Compared to the information found in literature, a span of 35 years for the development of a new HAWA site seems unrealistic (e.g. Squeo et al., 2006).

As also shown in other studies for different types of wetlands, Landsat ETM+ data revealed its high potentials for wetland mapping also in this study (Ozesmi and Bauer,
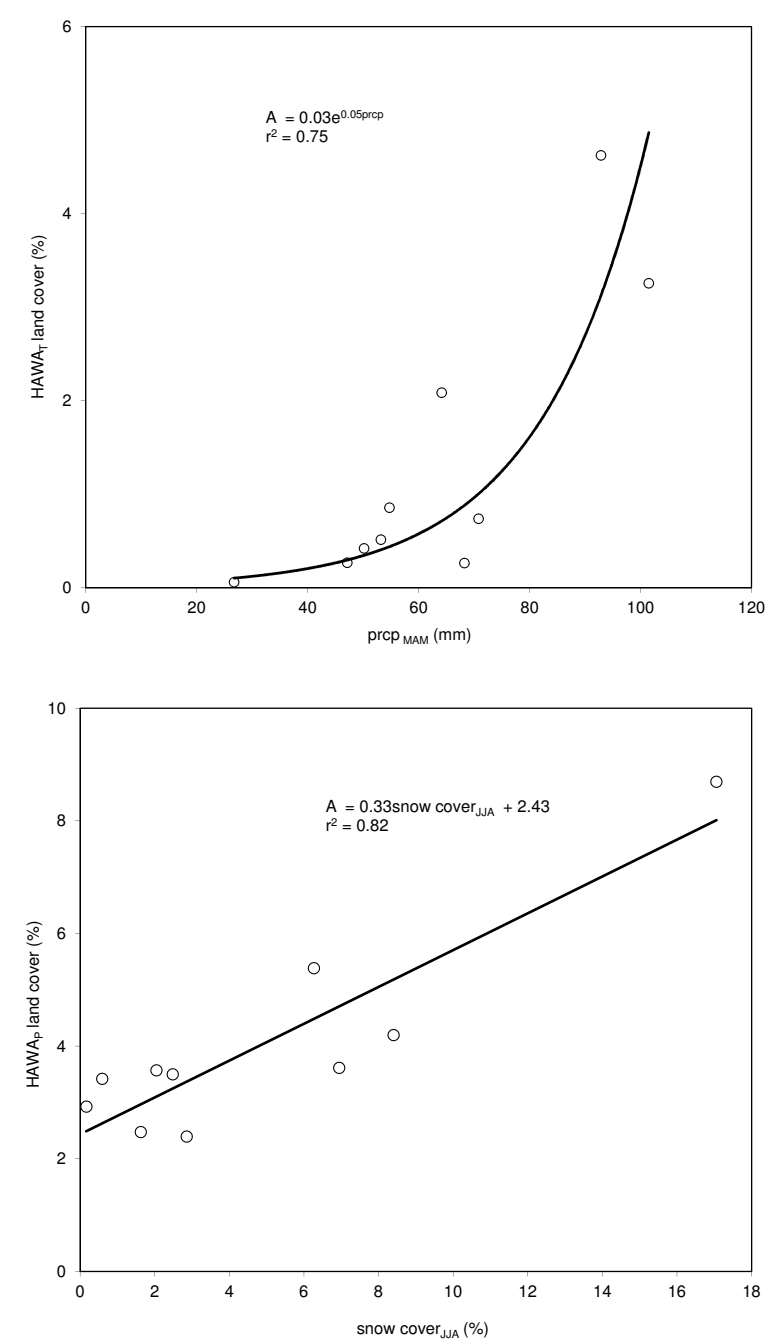

Fig. 11. Relation between prcp and snowcover JJA and HAWA land cover (bottom) of 2000 to 2010 .

2002). However, potential for continuous monitoring is limited due to restriction in data availability, we only found one set of adequate Landsat ETM+ data for the study region. Hence, a combination of Landsat ETM+ and MODIS NDVI data is recommended to enable time series analyses of spatial dynamics of HAWA subtypes at different spatial and temporal scales taking into account that MODIS NDVI data underestimates $\mathrm{HAWA}_{\mathrm{P}}$ and tends to overestimate $\mathrm{HAWA}_{\mathrm{T}}$ areas. Since this is probably due to lower spatial resolution of the MODIS sensors, MODIS based HAWA mapping results are systematically biased. Once this bias is quantitatively assessed as shown in this study monitoring and investigation on $\mathrm{HAWA}_{\mathrm{T}}$ and $\mathrm{HAWA}_{\mathrm{P}}$ at spatial resolution about seventy times lower then Landsat ETM+ was feasible.

As described in the HAWA mapping design HAWA $_{P, t f}$ and $\mathrm{HAWA}_{\mathrm{T}, \text { tf }}$ represent flooded areas within HAWA as generally expected for wetlands. HAWA ${ }_{P, \text { tf }}$ and $\mathrm{HAWA}_{\mathrm{T}, \mathrm{tf}}$ cover 
the smallest area of the study region. Although HAWA $_{P, t f}$ could cover up to $15 \%$ of a single HAWA site (Fig. 8 middle). The latter could also be related to precipitation because sites of relatively high precipitation contain more HAWA $_{P, \text { tf }}$ cover (Fig. 8 left $-720 \mathrm{~mm}$ and centre $490 \mathrm{~mm}$ ) than sites of lower precipitation (Fig. 8 right $-170 \mathrm{~mm}$ ).

Flooded areas of HAWA are suspected to contain pools with mineral bottoms probably representing residual shallow open-water areas that have not yet been overgrown by cushion-plants due to high stream velocities. Lower precipitation rates could generate lower stream velocities allowing cushion-plants to overgrow this aquatic environments and cause hydroseres promoting rapid peat accumulation as suggested for a single HAWA site found in northern Chile (Earle et al., 2003). The proposed methodology could be used to monitor this processes, but should be further evaluated. Unfortunately, MODIS time series data did not provide reasonable results for the multi annual mapping of $\mathrm{HAWA}_{\mathrm{P}, \mathrm{tf}}$ and HAWA $_{\text {, tf }}$ cover due to its coarser spatial resolution especially in $\rho_{\text {SWIR }}$ (Barnes et al., 1998).

HAWA $_{P}$ depends on run off generated from snowfall as also suspected in other studies (e.g., Ruthsatz et al., 2003; Squeo et al., 2006). In this study dependencies of HAWAP on snow fall was quantified at regional scale for the first time. However, Squeo et al. (2006) stated that the morphological character could be important at a single HAWA site. Although this was not within the focus of the study, spatial gradients as detected in Fig. 10 serve as an indicator to monitor plant water availability for PAV and should be investigated regarding the morphological setting within HAWA sites.

The existence of constantly mapped HAWAP might indicate dependencies to different water sources than annual snow cover or precipitation. The constantly mapped HAWAP could dependent on water sources, for example, water originated from glaciers or even fossil aquifers. At the ecological level regarding plant composition of HAWA we can conclude that on the one hand, the more constant HAWAP areas are best suited providing optimal hydrologic conditions for typical cushion-plant communities because they need constant (year-to-year) provision of water. On the other hand, HAWA $_{T}$ and less constant HAWAP should contain vegetation adopted to changes in plant water availability due to annual differences in precipitation.

HAWA $_{T}$ cover were controlled by precipitation occurring between March and May during austral summer. Changes in HAWAP $_{P}$ cover were controlled by snow events during June and August in austral winter. As depicted in Fig. 12 relation between $R H A W A_{\mathrm{P} / \mathrm{T}}$ and prcpmAM seems to be sensitive to changes in precipitation weakened by years of high snow cover (02_03). Hence, $R$ HAWAP/T might serve to monitor vegetation responds especially during years of unusual precipitation events within the high Andean region. HAWA subtypes are probably not only dependent on precipitation and annual changes could also be related to e.g., changing percolation rates due to erosion, auto regulation processes due

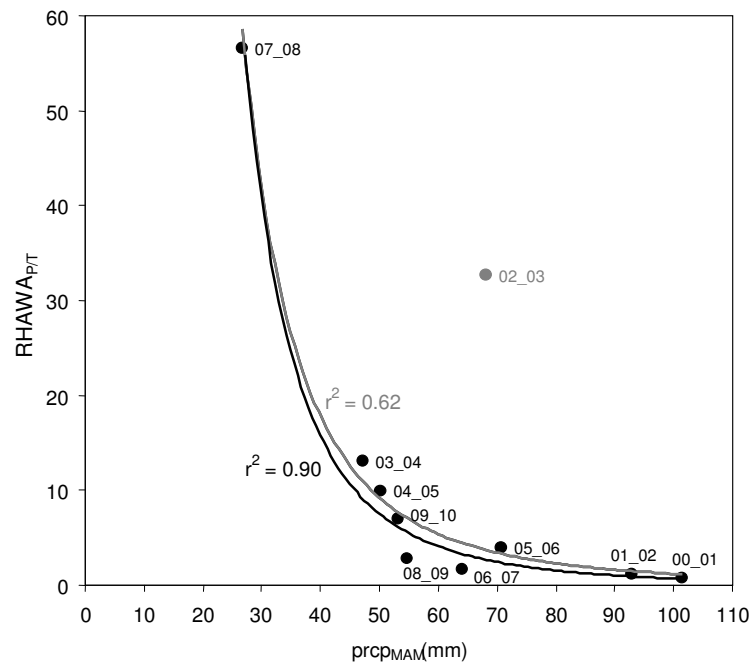

Fig. 12. Relation between prcp $\mathrm{MAM}$ and $R H A W A_{\mathrm{P} / \mathrm{T}}$. Grey fitted line is based on $R H A W A P / T$ and prcpMAM for all years $\left(r^{2}: 0.62\right)$ and black fitted line was computed without 02_03 (highest snow cover) $\left(r^{2}: 0.90\right)$.

to impact of vegetation growth on surface water flow paths (Fig. 3 - middle right), range land use (Fig. 3 - lower left) or changes in peat accumulation as also discussed by Earle et al. (2003).

\section{Conclusions}

The DT classifier was used for mapping of spatial distribution of HAWA within a sub-region of the central Andes. The mapping results served as a basis for hydrological differentiation of HAWA. The study showed that DT is an adequate method for the implementation of HAWA subtypes into a HAWA mapping procedure for the use of remotesensing data. The advantage of the proposed method lies in the simplicity of incorporating knowledge about HAWA based on a newly developed HAWA mapping design. Therefore, differentiation of HAWA into HAWA subtypes as found in literature and observed during field visits was possible through transformation of HAWA subtypes into HAWA subclasses for the use of two different remote-sensing datasets. The developed HAWA mapping procedure is applicable to remote-sensing data of different spatial resolution although over and underestimation effects have to be considered. A possible strategy for investigation on HAWA within other semi-arid high Andean regions could be to first perform a supervised multi-temporal land cover classification as proposed in this study based on Landsat ETM+ data and ground truth data derived from existing wetland inventories (e.g., topographic maps combined with field data). In a second step MODIS data could be implemented for time series analyses together with data of TRMM and MODIS snow cover 
Appendix A

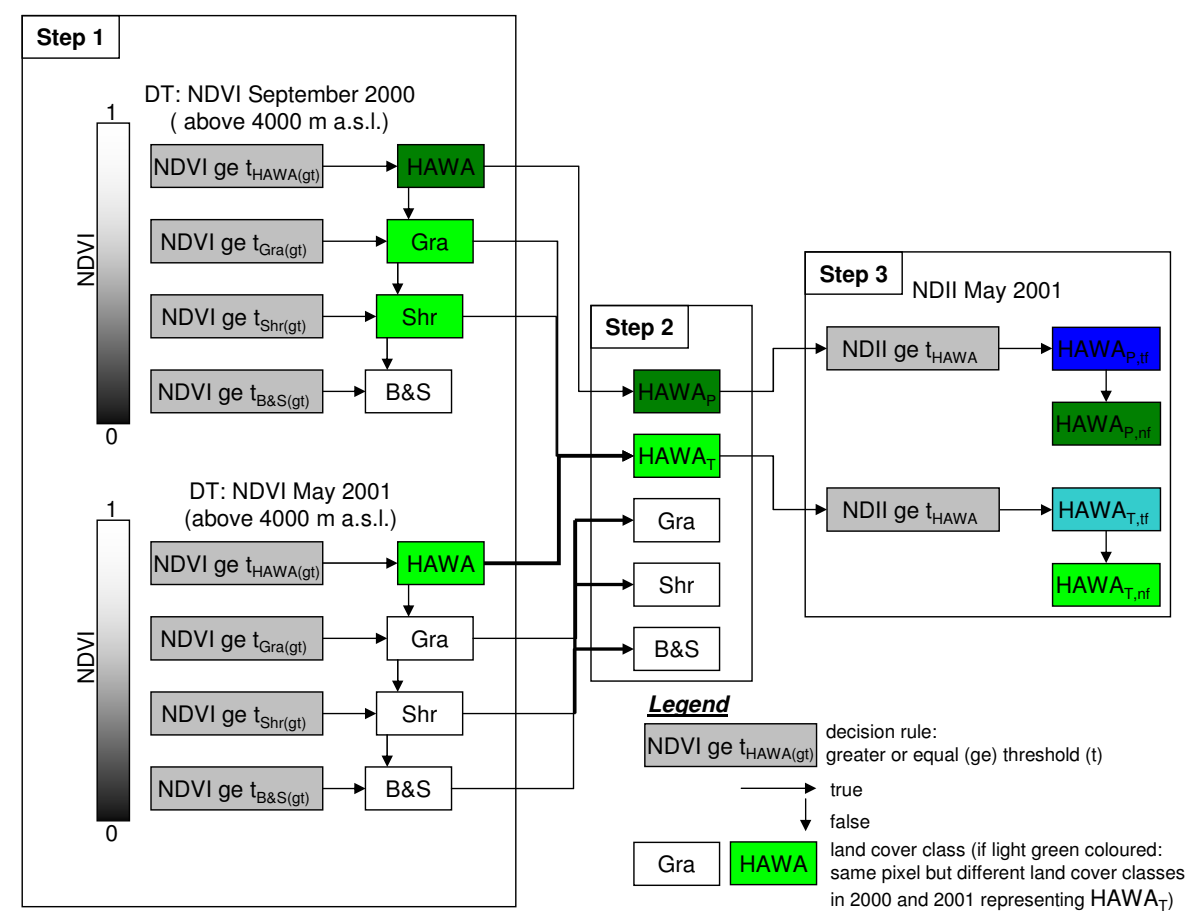

Fig. A1. HAWA mapping procedure: translation of the HAWA mapping design into a decision tree (DT) classifier for the use of remotesensing data.

data to investigate spatial and temporal changes of HAWA on precipitation within their whole distribution range. Since all remote-sensing datasets utilized for this study are free of charge and accessible via Internet, costs for data acquisition are very low.

The NDII represents vegetation of high plant water content or surface water content reflecting differences in hydrologic conditions within HAWA. Investigation on HAWA $\mathrm{H}_{\mathrm{tf}}$ and HAWA $_{\mathrm{T}, \mathrm{tf}}$ applying remote-sensing data is limited to data of higher spatial resolution (less than or equal to $30 \mathrm{~m}$ ). Hence, the use of Landsat ETM+ is recommended for further investigations on $\mathrm{HAWA}_{\mathrm{ft}}$. Open water or water saturated areas as defined for HAWA $_{\mathrm{ft}}$ are essential aquatic features of wetlands in general and in particular within semi-arid climates providing habitats for endemic flora and fauna of the Andes. The combination of the two vegetation indices provides valuable information on the spatial relation between the aquatic part (e.g., HAWA $\left.{ }_{P, t f}\right)$ and non-aquatic parts (e.g., HAWAP,nf) of HAWA.

The results of the study indicate that first of all HAWA are a widespread type of wetland within the semi-arid high Andes. The applied methodology and data has great potential for initiating a HAWA-inventory for these often remote regions. Secondly, HAWA are ecosystems containing parts that are connected to hydrological processes through run off generated from snowmelt (HAWAP). While other parts $\left(\mathrm{HAWA}_{\mathrm{T}}\right)$ are more dependent on direct precipitation during the transitional period of austral summer to austral winter time (MAM). It must be further evaluated if these finding can be concluded in other regions where HAWA occur and how this processes are connected to regional climates. And finally, spatial gradients of perennial HAWA enable monitoring of annual plant water availability for PAV at a single HAWA site over the last decade. These findings need to be further investigated at selected HAWA sites to evaluate results from hydrologic models with in situ measurements and remote sensing. An important question is if the observed spatial changes have any consequences for the ecosystem functions usually related with wetlands, for example, water storage capacity, biomass production or provision of critical habitat features for flora and fauna of the semi-arid high Andes. Combining the potential results with regional climate models could serve as bases to evaluate effects of climate change on the regional hydrologic circle of the high Andes using HAWA as proxies detecting hydrological and, hence, ecological consequences of projected decrease in precipitation, increase of temperatures and increased tropical glacier retreat. The results of the study provide a basis for further investigation on the complexity of HAWA with regard to their hydrological functioning towards a scientifically sound long term management within a region of the high Andes probably facing a future scenario of decreasing precipitation and increasing water demand. 
Acknowledgements. We acknowledge Philipp Buss, former head of the project COPASA-GTZ in Arequipa/Peru, for providing valuable support in transportation and equipment during field studies.

Edited by: S. Thompson

\section{References}

Baied, C. A. and Wheeler, J. C.: Evolution of high Andean puna ecosystems: environment, climate, and culture change over the last 12000 years in the Central Andes, Mt. Res. Dev., 13(2), 145156, 1993.

Barnes, W. L., Pagano, T. S., and Salomonson, V. V.: Prelaunch characteristics of the Moderate Resolution Imaging Spectroradiometer (MODIS) on EOS-AM1, IEEE T. Geosci. Remote, 36(4), 1088-1100, 1998.

Chander, G., Markham, B., and Helder, D.: Summary of current radiometric calibration coefficients for Landsat MSS, TM, ETM+, and EO-1 ALI sensors, Remote Sens. Environ., 113, 893-903, 2009.

Chatterjee, A., Blom, E., Gujja, B., Jacimovic, R., Beevers, L., O'Keeffe, J., Beland, M., and Biggs, T.: WWF Initiatives to study the impact of climate change on Himalayan high-altitude wetlands (HAWs), Mt. Res. Dev., 30(1), 42-52, 2010.

Coronel, J. S., Declerck, S., Maldonado, M., Ollevier, F., and Brendonck, L.: Temporary shallow pools in high-Andes "bofedal" peatlands: a limnological characterization at different spatial scales, Arch. Sci., 57(2-3), 85-96, 2004.

Davidson, A., Wang, S., and Wilmshurst, J.: Remote sensing of grassland-shrubland vegetation water content in the shortwave domain, Int. J. Appl. Earth Obs., 8(4), 225-236, 2006.

Earle, L. R., Warner, B. G., and Aravena, R.: Rapid development of an unusual peat-accumulating ecosystem in the Chilean Altiplano, Quaternary Res., 59(1), 2-11, 2003.

Friedl, M. A. and Brodley, C. E.: Decision tree classification of land cover from remotely sensed data, Remote Sens. Environ., 61, 399-409, 1997.

Hardisky, M., Klemas, V., and Smart, R.: The influence of soil salinity, growth form, and leaf moisture on the spectral radiance of Spartina alterniflora canopies, Photogramm. Eng. Rem. S., 49(1), 77-83, 1983.

Huete, A., Didan, K., Miura, T., Rodriguez, E., Gao, X., and Ferreira, L.: Overview of the radiometric and biophysical performance of the MODIS vegetation indices, Remote Sens. Environ., 83, 195-213, 2002.

IAI: Carta Nacional del Peru, scale: 1:100 000, map sheet 31s-t33s-t. IGNP, Lima NIMA (\&IGNP), Washington and Lima, topographic map collection of Ibero-American Institute (IAI), Berlin, 2010 .

Immerzeel, W., Rutten, M., and Droogers, P.: Spatial downscaling of TRMM precipitation using vegetative response on the Iberian Peninsula, Remote Sens. Environ., 113, 362-370, 2009.
INRENA: Evaluacion ambiental de la cuenca del rio Chili, Instituto Nacional de Recursos Naturales (INRENA), Rep., Lima, Peru, 2002.

Jackson, R. D. and Huete, A. R.: Interpreting vegetation indexes, Prev. Vet. Med., 11(3-4), 185-200, 1991.

Loveland, T., Reed, B., Brown, J., Ohlen, D., Zhu, Z., Yang, L., and Merchant, J.: Development of a global land cover characteristics database and IGBP DISCover from $1 \mathrm{~km}$ AVHRR data, Int. J. Remote Sens., 21(6-7), 1303-1330, 2000.

Moreau, S., Bosseno, R., Gu, X. F., and Baret, F.: Assessing the biomass dynamics of Andean bofedal and totora high-protein wetland grasses from NOAA/AVHRR, Remote Sens. Environ., 85(4), 516-529, 2003.

Myneni, R. B., Hall, F. G., Sellers, P. J., and Marshak, A. L.: Interpretation of spectral vegetation indexes, IEEE T. Geosci. Remote, 33(2), 481-486, 1995.

Naranjo, L. G.: An evaluation of the first inventory of South American wetlands, Vegetatio, 118, 125-129, 1995.

Ozesmi, S. and Bauer, M.: Satellite remote sensing of wetlands, Wetl. Ecol. Manag., 10(5), 381-402, 2002.

Richter, M.: Klimagegensätze in Südperu und ihre Auswirkungen auf die Vegetation, Erdkunde, 35, 12-30, 1981.

Ruthsatz, B.: Flora and ecological conditions of high Andean peat-

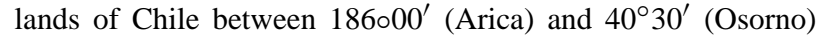
south latitude, Phytocoenologia, 23, 157-199, 1993.

Ruthsatz, B.: Die Hartpolstermoore der Hochanden und ihre Artenvielfalt, Ber. D. Reinh.-Tüxen-Ges., 12, 185-234, 2000.

Scott, D. A. and Carbonell, M.: A Directory of Neotropical Wetlands, IUCN Cambridge and IWRB Slimbridge, 1986.

Squeo, F. A., Warner, B. G., Aravena, R., and Espinoza, D.: Bofedales: high altitude peatlands of the Central Andes, Rev. Chil. Hist. Nat., 79(2), 245-255, 2006.

Tapia, M.: Mountain agrobiodiversity in Peru: seed fairs, seed banks, and mountain-to-mountain exchange, Mt. Res. Dev., 20(3), 220-225, 2000.

Troll, C.: The cordilleras of the tropical Americas, Aspects of climatic, phytogeographical and agrarian ecology, in: Colloquium Geographicum, Band 9, edited by: Troll, C., Geoecology of the Mountainous Regions of the Tropical Americas, Proceedings of the UNESCO Mexico Symposium 1966, 15-56, 1968.

Tucker, C.: Red and photographic infrared linear combination for monitoring vegetation, Remote Sens. Environ., 8, 127-150, 1979.

Vuille, M., Francou, B., Wagnon, P., Juen, I., Kaser, G., Mark, B. G., and Bradley, R. S.: Climate change and tropical Andean glaciers: past, present and future, Earth-Sci. Rev., 89(3-4), 79-96, 2008.

Wetlands International: Ramsar Sites Information Service, http:// ramsar.wetlands.org, last access: 11 October 2010, Wageningen, Netherlands, 2010.

Wilcox, B., Bryant, F., Wester, D., and Allen, B.: Grassland communities and soils on a high elevation grassland of Central Peru, Phytologia, 61, 231-250, 1986. 